American Journal of Economics and Business Administration 2 (3): 210-220, 2010

ISSN 1945-5488

(C) 2010 Science Publications

\title{
Investment, Taxes and the Cost of Capital: An Euler Equation Specification Test
}

\author{
Huntley Schaller \\ Department of Economics, Carleton University, Canada
}

\begin{abstract}
Problem statement: Previous studies (primarily employing goodness-of-fit tests) have found it difficult to provide clear and direct evidence that taxes and the interest rate have a strong influence on investment. Approach: The objective of this study was to test whether the cost of capital, which includes taxes and the interest rate, affects investment. This study used the Euler equation for investment, the Generalized Method of Moments estimator and the associated test of overidentifying restrictions (J statistic). Specifications including and excluding components of the tax system were estimated and the resulting $\mathrm{J}$ statistics were compared. This study also examined two potential problems with measuring another component of the cost of capital (the interest rate): (1) risk; (2) finance constraints. To examine the second issue, the Euler equation is modified by parameterizing the Lagrange multiplier on the finance constraint. The models with and without finance constraints were compared using a Newey-West test. Results: Including taxes in the investment Euler equation reduced evidence of misspecification. In particular, including the investment tax credit, the corporate tax rate and interest deductibility, respectively, all lead to lower $\mathrm{J}$ statistics than omitting these tax considerations. Using a risky interest rate instead of the risk-free interest rate makes little difference. The Newey-West test rejected the model without finance constraints. Parametric estimated of the model with finance constraints suggest that variations in the tightness with which finance constraints bind lead to substantial variation in the effective discount rate. Taxes continue to matter in the model that incorporates finance constraints. Conclusion: The results suggested that the cost of capital (specifically, the tax system) influences investment and finance constraints are important.
\end{abstract}

Key words: Investment, corporate taxation, cost of capital, specification tests, investment Euler equation

\section{INTRODUCTION}

Economists frequently emphasize the role of prices in determining the allocation of goods. In the case of investment, the relevant price is the cost of capital, which reflects the interest rate and taxes. Surprisingly, it has been hard to find clear evidence that the cost of capital affects investment.

The first generation of tests were based on the goodness of fit of different investment models. The neoclassical investment model pioneered by Jorgensen and others emphasized the role of the cost of capital. Especially when the neoclassical model includes long distributed lags, it tends to fit the data well, suggesting that the cost of capital influences investment. This interpretation has been criticized, however, because in the neoclassical model, tax variables enter together with output. Since investment is strongly correlated with output, there is some concern that entering the cost of capital in combination with output exaggerates the role of interest rates and taxes. This concern is reinforced by the fact that the accelerator model which allows no role for the cost of capital, tends to fit just about as well (Pindyck, 1991). On the basis of tests using the neoclassical approach, it has therefore been difficult to persuade skeptics that the interest rate and taxes have a strong influence on investment.

Many economists prefer the Q model on theoretical grounds because it takes advantage of market prices (specifically, the stock market value of firms) to capture expectations (Chirinko, 1993). Initial empirical work based on the $\mathrm{Q}$ approach was promising in that it suggested an important role for taxes (Summers, 1981). As time has passed, enthusiasm for the Q model has diminished noticeably, partly because of its poor empirical performance (Abel and Blanchard, 1986). Movements in Q generally explain only a small part of the variation in investment. The unexplained portion is highly serially correlated, particularly in aggregate data. The estimated adjustment costs imply that the reaction of investment to tax changes is extremely slow. Finally, variables which should not matter according to the 
standard Q theory significantly affect investment. Beyond the poor empirical performance of the $Q$ model, it is subject to the same critique as the neoclassical model, namely that the effect of taxes is measured indirectly. The tax variables are incorporated in the construction of $\mathrm{Q}$, so tax rates enter in combination with other variables. Since most of the variation in $\mathrm{Q}$ comes from stock market prices, the estimated effects of taxes may be piggybacking on stock prices.

This study pursues a different approach to determining whether the cost of capital affects investment. This approach focuses on the Euler equation for investment and draws on the Generalized Method of Moments estimator proposed by Hansen (1982). In particular, this study uses the associated specification test as a way of testing whether or not the cost of capital affects investment (Hubbard and Kashyap, 1992; Whited, 1992). A prior paper that uses the investment Euler equation to test for the effect of the cost of capital -- and specifically taxes -- is Devereux et al. (1994), who use a slightly different approach and completely different data.

The details of the specification test are somewhat technical, but the key idea is very intuitive. Under rational expectations, the error term in the Euler equation should reflect expectational errors and should therefore be orthogonal to information available in the previous period. If the Euler equation is misspecified, perhaps because tax variables have been omitted, the error term will contain more than expectational errors and may therefore be correlated with tax rates or other information available in the previous period. The $\mathrm{J}$ test presents a new type of evidence on the role of taxes and interest rates (The $\mathrm{J}$ test is also frequently referred to as the Sargan test).

There are good reasons for thinking that the Euler equation approach has a better chance of providing clear evidence on whether the cost of capital affects investment. The most important reason is that the Euler equation approach is superior in the way that it handles expectations. Economists believe that investment spending depends on the expected future stream of income generated by a new unit of capital. This poses both the firm and the econometrician with a difficult problem: The future is unknown and hard to predict.

The neoclassical approach fails to satisfactorily address this problem; instead, it uses an ad hoc approach based on adaptive expectations. In pragmatic terms, this approach may obscure the effects of the interest rate and taxes because it includes many lagged values of variables. The estimated coefficients on these lags lack a clear structural interpretation and may be poorly estimated because they are not stable parameters but are themselves functions of the interest rate and taxes. In other words, this may be a situation in which the Lucas critique is of substantial practical importance.

In principle, the $\mathrm{Q}$ approach uses a more sophisticated strategy which is consistent with rational expectations. If the stock market is efficient in the sense that the stock market price corresponds to the present value of the firm's future earnings, the $\mathrm{Q}$ approach could work very well. If the stock market is not efficient (in this rather restrictive sense), Q may be measured with error and the estimated coefficients in the $\mathrm{Q}$ investment equation could therefore be biased (For heuristic reasons, we discuss the measurement error issue in terms of stock market efficiency. There are many other reasons, however, why $\mathrm{Q}$ might be measured with error.). In fact, empirical studies using the Q approach yield estimated adjustment costs which are economically implausible.

The Euler equation approach is based on the insight that the firm's problem is recursive. As long as the firm makes the optimal tradeoff between investment today and investment tomorrow, it will choose the same time path for investment as it would if it based its decision on the whole future stream of expected marginal products of capital. The informational requirements (both for the firm and the econometrician) of predicting the next period are much less stringent than those for predicting the entire future stream of profitability. For the econometrician, this is why the Euler equation offers greater promise of clear results on the role of the cost of capital.

This study applies the Euler equation approach to panel data on Canadian firms over the period 1973-86. The use of panel data is potentially important for two reasons. First, there are theoretical reasons (and empirical evidence) which suggest that some of the apparently sluggish response of investment to changes in the cost of capital arises from aggregation Bertola and Caballero (1994), who argue that aggregate dynamics should be interpreted as unsynchronized irreversible investment decisions by heterogeneous firms, rather than in terms of a representative-agent framework. Using panel data on US firms, Schaller (1990) finds that aggregation is responsible for spurious evidence of dynamic misspecification and at least partially responsible for high estimated adjustment costs.). Second, not all firms are in the same position with respect to capital markets. Again, both theoretical models and empirical evidence suggest that this is important in understanding the response of investment to changes in the cost of capital (Fazzari et al., 1988) was a pioneering paper in 
the recent literature; Gertler (1988) provides a survey and further references on the theoretical literature).

The main empirical conclusion of this study is that the cost of capital influences investment. In particular, the $\mathrm{J}$ statistics are larger (implying greater misspecification) when taxes are omitted. These results provide an entirely new type of evidence that taxes affect investment.

The specification test evidence is not subject to many of the criticisms which have been made of previous studies. The entire specification is explicitly derived from the optimization problem of the firm. In particular, no lagged values of variables have been arbitrarily added. Even more important, the evidence on the role of taxes comes from a comparison of specifications in which tax terms are included or excluded. The evidence on the role of taxes is therefore direct; it does not arise because taxes enter in combination with other variables, such as output or stock market prices, as in previous empirical studies based on the neoclassical or Q models.

The very fact that the Euler equation approach allows tax terms to be entered separately may help to account for the relatively clear evidence on the cost of capital presented in this study. In the neoclassical approach, tax provisions (such as the investment tax credit) enter in combination with the interest rate. It has sometimes been argued that the difficulty in measuring the interest rate is a key reason for the weak evidence on the cost of capital. Two possible problems in measuring the real interest rate are the difficulties in modeling inflation expectations and the choice of risk premium. This study provides some evidence that these problems are not very important, but that there is a much more serious problem in measuring the relevant interest rate.

In a world of symmetric information, the Modigliani-Miller theorem applies: A firm chooses its desired investment and then, if it does not have enough internal financing to carry out the project, raises the necessary funds on the capital market. In standard theory, investment therefore depends on the market interest rate. A new theoretical literature has emphasized the role of asymmetric information and how this can lead to finance constraints on firms. When a finance constraint binds, the shadow cost of financing can diverge from the market interest rate. Since it is the shadow cost of finance which determines investment, the usual cost of capital variable (which is largely driven by the market interest rate) will perform poorly in explaining investment (Studies on inventory investment have also found little relationship between interest rates and inventories. Kashyap et al. (1994) find that this may also be due to finance constraints; in particular, they suggest that the spread between the interest rate on bank loans and other types of financing may widen at times of tight monetary policy, implying a much greater increase in financing costs for firms which rely heavily on bank loans for working capital than would be suggested by securities market interest rates).

To test the idea that binding finance constraints help to explain why it has been difficult to find a strong link between the cost of capital and investment, the original model is extended to incorporate borrowing constraints into the firm's optimization problem. This leads to a new empirical specification for the Euler equation. Controlling for finance constraints (by using the new Euler equation) dramatically reduces the $\mathbf{J}$ statistics. The new specification also allows us to parametrically estimate the magnitude of the wedge between the shadow cost of financing and the market interest rate. It turns out that a relatively small change in the firm's environment leads to a change in the shadow cost of financing of more than 700 basis points; this compares to an average real interest rate of $4 \%$ over the 1973-86 sample period.

The study is structured as follows. In the section entitled "Materials And Methods," we derive the investment Euler equation. In the section entitled "Results," we do three things. First, we present specification test results for the investment Euler equation in which tax considerations are either omitted or included. Second, we explain why the shadow interest rate diverges from the market interest rate if finance constraints bind, illustrate why this may lead to rejection of the investment Euler equation and derive an alternative investment Euler equation which incorporates finance constraints. Third, we present empirical estimates of the Euler equation which allow for finance constraints. In addition, we test whether taxes affect investment even after allowance has been made for finance constraints. In the section entitled "Discussion," we summarize the main empirical results and offers conclusions.

\section{MATERIALS AND METHODS}

Derivation of empirical specification: Here the Euler equation which will be used in the econometric tests is derived. Before starting the derivation, it may be useful to emphasize why the Euler equation approach may have a better chance of capturing cost of capital effects than other approaches. Because the Euler equation represents a period-to-period arbitrage condition, we need only model expectations of the next period, not the 
entire future stream of marginal products of capital. Moreover, under rational expectations, we can replace expected values with actual values plus an expectation error (Although it is not obvious how we could test the assumption of rational expectations, we can at least test the joint hypothesis of rational expectations plus the specification derived from our model. As we adjust the specification, we obtain evidence on how much of the tendency to reject the joint hypothesis is due to aspects of the model other than rational expectations.). By simplifying the problem of modeling expectations, the Euler equation approach has the potential to strip away some of the complications which could account for the difficulty in finding evidence that the cost of capital matters.

The unconstrained optimization problem for the firm is:

$$
\begin{aligned}
& \max _{\left\{I_{t}, L_{t}, B_{t}\right\}} E_{t} \sum_{j=0}^{\infty} R_{t+j}\left[( 1 - \tau _ { t + j } ) \left[p_{t+j} F\left(K_{t+j}, L_{t+j}\right)-G\left(I_{t+j}, K_{t+j}\right)\right.\right. \\
& \left.\left.-w_{t+j} L_{t+j} r_{t+j-1} B_{t+j-1}\right]-\left(1-k_{t+j}-\tau_{t+j} Z_{t+j}\right) p_{t}^{I} I_{t+j}+B_{t+j}-B_{t+j}\right]
\end{aligned}
$$

s.t. $\mathrm{K}_{\mathrm{t}+\mathrm{j}}=(1-\delta) \mathrm{K}_{\mathrm{t}+\mathrm{j}-1}+\mathrm{I}_{\mathrm{t}+\mathrm{j}}$

Where:

$$
\mathrm{R}_{\mathrm{t}+\mathrm{j}}=\prod_{\mathrm{i}=\mathrm{t}+1}^{\mathrm{t}+\mathrm{j}} \beta_{\mathrm{i}}
$$

Where:

$$
\begin{array}{ll}
\mathrm{E}_{\mathrm{t}} & =\text { The expectations operator conditional on } \\
& \text { information available at time } \mathrm{t} \\
\mathrm{I}_{\mathrm{t}} & =\text { Investment in period } \mathrm{t} \\
\beta_{\mathrm{t}} & =\text { The discount factor } \\
\tau_{\mathrm{t}} & =\text { The corporate tax rate } \\
\mathrm{L}_{\mathrm{t}} & =\text { Variable inputs } \\
\mathrm{p}_{\mathrm{t}} & =\text { The price of output } \\
\mathrm{F}(\mathrm{K}, \mathrm{L}) & =\text { The production function } \\
\mathrm{K}_{\mathrm{t}} & =\text { The capital stock } \\
\mathrm{G}(\mathrm{I}, \mathrm{K}) & =\text { The adjustment cost function } \\
\mathrm{w}_{\mathrm{t}} & =\text { The price of variable inputs } \\
\mathrm{p}_{\mathrm{t}}^{\mathrm{I}} & =\text { The price of investment goods } \\
\mathrm{k}_{\mathrm{t}} & =\text { The investment tax credit rate } \\
\mathrm{z}_{\mathrm{t}} & =\text { The present value of future depreciation } \\
& \text { allowances } \\
\mathrm{r}_{\mathrm{t}} & =\text { The real interest rate on the firm's stock of } \\
\mathrm{B}_{\mathrm{t}} & =\text { The stock of one-period debt } \\
\delta & =\text { The depreciation rate }
\end{array}
$$

In order to allow for a simple form of imperfect competition, this study assumes a CES demand function $\left(\mathrm{p}=\mathrm{Y}^{-\psi}\right)$ where $\mathrm{Y}$ is output.

Since the dynamic optimization problem of the firm is well known, only the first order conditions which are relevant in deriving the empirical specification are described. The first order condition for capital is:

$$
\left(1-\tau_{t}\right)(1-\psi) \mathrm{p}_{\mathrm{t}} \mathrm{F}_{\mathrm{K}, \mathrm{t}}-\left(1-\tau_{\mathrm{t}}\right) \mathrm{G}_{\mathrm{K}, \mathrm{t}}-\lambda_{\mathrm{t}}^{\mathrm{K}}+\mathrm{E}_{\mathrm{t}} \beta_{\mathrm{t}}(1-\delta) \lambda_{\mathrm{t}+\mathrm{j}}^{\mathrm{K}}=0
$$

where, $\mathrm{K} 1$ is the Lagrange multiplier on capital. The first order condition on investment is:

$\lambda_{t}^{\mathrm{K}}=\left(1-\mathrm{k}_{\mathrm{t}}-\tau_{\mathrm{t}} \mathrm{z}_{\mathrm{t}}\right) \mathrm{p}_{\mathrm{t}}^{\mathrm{I}}+\left(1-\tau_{\mathrm{t}}\right) \mathrm{G}_{\mathrm{I}, \mathrm{t}}$

The first order condition for variable inputs is:

$\mathrm{w}_{\mathrm{t}}=(1-\psi) \mathrm{p}_{\mathrm{t}} \mathrm{F}_{\mathrm{L}, \mathrm{t}}$

The first order condition for net new loans is:

$1-\beta_{t}\left[\left(1-\tau_{t+1}\right) r_{t}+1\right]=0$

If the interest tax shield is omitted, the firm's discount factor is therefore equal to $1 /(1+r)$.

In order to empirically estimate these equations, we must make assumptions about functional form. It is assumed that the production function is Cobb-Douglas; to allow for nonconstant returns to scale, a production function is assumed to be homogeneous of degree $\eta$, where, $\eta=\alpha_{K}+\alpha_{L}$ :

$\mathrm{F}(\mathrm{K}, \mathrm{L})=\mathrm{K}^{\alpha_{\mathrm{K}}} \mathrm{L}^{\alpha_{\mathrm{L}}}$

As is standard in the investment literature, quadratic adjustment costs are assumed, specifically of the form:

$$
\mathrm{G}(\mathrm{I}, \mathrm{K})=\frac{\phi}{2}\left(\frac{\mathrm{I}}{\mathrm{K}}\right)^{2} \mathrm{~K}
$$

where, $\phi$ is the marginal adjustment cost parameter. The assumptions on the form of the production function imply that:

$$
\mathrm{F}_{\mathrm{K}} \mathrm{K}+\mathrm{F}_{\mathrm{L}} \mathrm{L}=\eta \mathrm{F}
$$

This allows us to express the value marginal product of capital as: 


$$
\begin{aligned}
(1-\psi) \mathrm{pF}_{\mathrm{K}} & =\frac{(1-\psi) \eta \mathrm{pF}}{\mathrm{K}}-\frac{(1-\psi) \mathrm{pF}_{\mathrm{L}} \mathrm{L}}{\mathrm{K}} \\
& =\frac{(1-\psi) \eta p F}{\mathrm{~K}}-\frac{\mathrm{wL}}{\mathrm{K}} \\
& =\frac{(1-\psi) \eta p F}{\mathrm{~K}}-\frac{\mathrm{C}}{\mathrm{K}}
\end{aligned}
$$

where, $\mathrm{C}$ is the cost of variable factors of production.

In order to derive the empirical specification for the Euler equation, take the following steps. First, substitute the first-order condition for investment into the first-order condition for capital. Second, substitute in the functional forms which have been assumed. Third, rearrange the resulting expression so that the terms associated with common parameters are grouped together. Finally, replace expectations with actual future values plus an expectational error. This yields the following equation:

$$
\begin{gathered}
\left(1-\tau_{\mathrm{t}}\right) \frac{\mathrm{p}_{\mathrm{t}} \mathrm{Y}_{\mathrm{t}}}{\mathrm{K}_{\mathrm{t}}}-\frac{1}{(1-\psi) \eta}\left[\begin{array}{l}
1-\tau_{\mathrm{t}} \frac{\mathrm{C}_{\mathrm{t}}}{\mathrm{K}_{\mathrm{t}}}+\left(1-\mathrm{k}_{\mathrm{t}}-\tau_{\mathrm{t}} \mathrm{z}_{\mathrm{t}}\right) \mathrm{p}_{\mathrm{t}}^{\mathrm{I}} \\
-\left(\frac{1}{1+\left(1-\tau_{\mathrm{t}+1}\right) \mathrm{r}_{\mathrm{t}}}\right)(1-\delta)\left(1-\mathrm{k}_{\mathrm{t}+1}-\tau_{\mathrm{t}+1} \mathrm{Z}_{\mathrm{t}+1}\right) \mathrm{p}_{\mathrm{t}+1}^{\mathrm{I}}
\end{array}\right] \\
-\frac{\phi}{(1-\psi) \eta}\left[\begin{array}{l}
\left(1-\tau_{\mathrm{t}}\right)\left(\frac{\mathrm{I}_{\mathrm{t}}}{\mathrm{K}_{\mathrm{t}}}-.5\left(\frac{\mathrm{I}_{\mathrm{t}}}{\mathrm{K}_{\mathrm{t}}}\right)^{2}\right)-\left(\frac{1}{1+\left(1-\tau_{\mathrm{t}+1}\right) \mathrm{r}_{\mathrm{t}}}\right) \\
(1-\delta)\left(1-\tau_{\mathrm{t}+1}\right)\left(\frac{\mathrm{I}_{\mathrm{t}+1}}{\mathrm{~K}_{\mathrm{t}+1}}\right)
\end{array}\right]=\mathrm{e}_{\mathrm{t}}
\end{gathered}
$$

where, $e_{t}$ is the expectational error. Under rational expectations, this should be orthogonal to variables in the information set at $\mathrm{t}-1$.

It may be helpful to provide an intuitive explanation. The Euler equation is a period-toperiod arbitrage condition with the following feasible perturbation interpretation: Holding the capital stock constant in all other periods, a firm will choose the timing of its investment between two adjacent periods in order to equate the marginal costs and benefits across the periods. Under standard assumptions, the marginal costs and benefits will be determined by the firm's expectations of the price of investment goods and the corporate tax rate in the two adjacent periods, marginal adjustment costs, the interest rate and the marginal product of capital. In standard theoretical treatments, it is the effective price of investment which matters; this reflects tax provisions such as the investment tax credit and depreciation allowances.

\section{RESULTS AND DISCUSSION}

Specification test results: Here empirical estimates of the Euler equation for investment (derived in Section 1) are presented. The strategy is to estimate the Euler equation with tax terms included and omitted. In this way, we can determine whether the inclusion of tax effects reduces evidence of misspecification.

Equation 12 describes the investment behavior of firms. In particular, under rational expectations, the error term will simply be $e_{t}$, an expectation error and should be orthogonal to variables in the information set at time $\mathrm{t}-1$. As discussed above, this study uses GMM estimation because it is based on this orthogonality restriction and because it permits us to test the implied over identifying restrictions. Consistent with this, the instruments are lagged values of the variables that appear in the Euler equation (Specifically, the instruments are the $\mathrm{t}-2$ values of $\mathrm{pY} / \mathrm{K}, \mathrm{C} / \mathrm{K}, \mathrm{p}^{\mathrm{I}}, \tau, \delta \mathrm{I} / \mathrm{K}$, $(\mathrm{I} / \mathrm{K})^{2}$ and $\mathrm{S} . \mathrm{S}$ is included to ensure that the instrument set is the same for specifications here and when we allow for finance constraints (below). To eliminate fixed firm effects, the Euler is first-differenced. The weighting matrix used in the GMM estimation is adjusted for the MA(1) serial correlation introduced by first-differencing).

The effective price of investment: According to standard investment models, the effective price of investment is:

$$
\left(1-k_{t}-\tau_{t} z_{t}\right) p_{t}^{I}
$$

It is possible to omit the investment tax credit $\left(\mathrm{k}_{\mathrm{t}}\right)$ and depreciation allowances $\left(\tau_{t} z_{t}\right)$ in estimating the Euler equation. If these tax considerations actually influence investment spending, the Euler equation will then be misspecified and the tax terms will show up in the error term of the regression:

$$
\begin{aligned}
& \left(1-\tau_{\mathrm{t}}\right) \frac{\mathrm{P}_{\mathrm{t}} \mathrm{Y}_{\mathrm{t}}}{\mathrm{K}_{\mathrm{t}}}-\frac{1}{(1-\psi) \eta}\left[\begin{array}{l}
\left(1-\tau_{\mathrm{t}}\right) \frac{\mathrm{C}_{\mathrm{t}}}{\mathrm{K}_{\mathrm{t}}}+\mathrm{p}_{\mathrm{t}}^{\mathrm{I}}- \\
\left(\frac{1}{1+\left(1-\tau_{\mathrm{t}+1}\right) \mathrm{r}_{\mathrm{t}}}\right)(1-\delta) \mathrm{p}_{\mathrm{t}+1}^{\mathrm{I}}
\end{array}\right] \\
& -\frac{\phi}{(1-\psi) \eta}\left[\begin{array}{l}
\left(1-\tau_{\mathrm{t}}\right)\left(\frac{\mathrm{I}_{\mathrm{t}}}{\mathrm{K}_{\mathrm{t}}}-.5\left(\frac{\mathrm{I}_{\mathrm{t}}}{\mathrm{K}_{\mathrm{t}}}\right)^{2}\right)-\left(\frac{1}{1+\left(1-\tau_{\mathrm{t}+1}\right) \mathrm{r}_{\mathrm{t}}}\right) \\
(1-\delta)\left(1-\tau_{\mathrm{t}+1}\right)\left(\frac{\mathrm{I}_{\mathrm{t}+1}}{\mathrm{~K}_{\mathrm{t}+1}}\right)
\end{array}\right] \\
& =\mathrm{e}_{\mathrm{t}}-\frac{1}{(1-\psi) \eta}\left[\begin{array}{l}
\left(1-\mathrm{k}_{\mathrm{t}}-\tau_{\mathrm{t}} \mathrm{z}_{\mathrm{t}}\right) \mathrm{p}_{\mathrm{t}}^{\mathrm{I}}-\left(\frac{1}{1+\left(1-\tau_{\mathrm{t}+1}\right) \mathrm{r}_{\mathrm{t}}}\right) \\
(1-\delta)\left(1-\mathrm{k}_{\mathrm{t}+1}-\tau_{\mathrm{t}+1} \mathrm{z}_{\mathrm{t}+1}\right) \mathrm{p}_{\mathrm{t}+1}^{\mathrm{I}}
\end{array}\right]
\end{aligned}
$$


Table 1: Investment, taxes and the effective price of investment

$$
\begin{aligned}
& \left(1-\tau_{\mathrm{t}}\right) \frac{\mathrm{Y}_{\mathrm{t}}}{\mathrm{K}_{\mathrm{t}}}-\frac{1}{(1+\mathrm{m}) \eta}\left[\left(1-\tau_{\mathrm{t}}\right) \frac{\mathrm{C}_{\mathrm{t}}}{\mathrm{K}_{\mathrm{t}}}+\mathrm{p}_{\mathrm{t}}^{\mathrm{I}}-\beta_{\mathrm{t}}(1-\delta) \mathrm{p}_{\mathrm{t}+1}^{\mathrm{I}}\right] \\
& -\frac{\phi}{(1-\mathrm{m}) \eta}\left[\left(1-\tau_{\mathrm{t}}\right)\left(\frac{\mathrm{I}_{\mathrm{t}}}{\mathrm{K}_{\mathrm{t}}}-.5\left(\frac{\mathrm{I}_{\mathrm{t}}}{\mathrm{K}_{\mathrm{t}}}\right)^{2}\right)-\beta_{\mathrm{t}}(1-\delta)\left(1-\tau_{\mathrm{t}+1}\right)\left(\frac{\mathrm{I}_{t+1}}{\mathrm{~K}_{\mathrm{t}+1}}\right)\right]=\mathrm{e}_{\mathrm{t}}
\end{aligned}
$$

\begin{tabular}{|c|c|c|}
\hline & $\phi$ & $(1+m) \eta$ \\
\hline Neither & $0.768(1.149)$ & $0.918(0.013) 35.2(0.0000)$ \\
\hline Depreciation allowances & $0.766(1.149)$ & $0.916(0.013) 36.1(0.0000)$ \\
\hline Investment tax credit & $0.357(0.795)$ & $0.913(0.012) \quad 24.9(0.0001)$ \\
\hline Both & $0.382(0.813)$ & $0.912(0.012) \quad 25.8(0.0001)$ \\
\hline $\begin{array}{l}\text { The estimation methoc } \\
\text { misspecification from } \mathrm{f} \\
\text { equation. The weighting } \\
\text { for the MA(1) serial corr } \\
\text { instruments are } \mathrm{t}-2 \text { valu } \\
\text { Robust standard errors } \\
\text { parameter estimates. The } \\
\text { is distributed } \mathrm{x}^{2} \text { with } \mathrm{d} \\
\text { overidentifying restrictic } \\
\text { instruments and } \mathrm{k} \text { is th } \\
\text { parentheses below the } \\
\text { levels }\end{array}$ & $\begin{array}{l}\text { is GMM. } \\
\text { fixed firm effe } \\
\text { matrix used in } \\
\text { relation introduc } \\
\text { es of } \mathrm{Y} / \mathrm{K}, \mathrm{C} / \mathrm{K} \\
\text { are presented } \\
\mathrm{J} \text {-test, which is } \\
\text { legrees of freed } \\
\text { ons (i.e., g-k, } \\
\text { le number of p } \\
\mathrm{J} \text { statistics are }\end{array}$ & $\begin{array}{l}\text { To avoid an econometric } \\
\text { ects, we first-difference the } \\
\text { GMM estimation is adjusted } \\
\text { ced by first-differencing. The } \\
\mathrm{K}, \mathrm{p}_{\mathrm{I}}, \mathrm{S}, \tau, \delta, \mathrm{I} / \mathrm{K} \text { and }(\mathrm{I} / \mathrm{K})^{2} \text {. } \\
\text { in parentheses below the } \\
\mathrm{s} \text { described in Hansen }(1982) \text {, } \\
\text { lom equal to the number of } \\
\text { where } \mathrm{g} \text { is the number of } \\
\text { arameters). The numbers in } \\
\text { their marginal significance }\end{array}$ \\
\hline
\end{tabular}

Variables in the information set at time t-1 may be correlated with these tax terms. If the error term is not orthogonal to the instruments, the over identifying restrictions may be rejected. The $\mathrm{J}$ statistic which tests these restrictions is distributed $\mathrm{x}^{2}$ with degrees of freedom equal to the number of over identifying restrictions, which is $g-p$, where $g$ is the number of instrument and $\mathrm{p}$ is the number of parameters. Since there are eight instruments and two parameters, there are six degrees of freedom.

The above discussion focuses on the case where standard investment models are correct. The test is symmetric, however; if standard investment models are wrong and the investment tax credit and depreciation allowances are irrelevant, omitting them will remove a source of misspecification and tend to reduce the $\mathrm{J}$ statistic.

Table 1 presents GMM estimates of the Euler equation. The first row is estimated with neither the investment tax credit nor depreciation allowances included in the effective price of investment. In other words, the first row presents estimates of Eq. 14 (The estimates in Table 1 exclude interest deductability; i.e., $(1-\tau) r$ in (14) is replaced by $r$. The effect of including interest deductability is examined below.). The $\mathbf{J}$ statistic is 35.2, which strongly suggests misspecification: The marginal significance level for rejection of the null hypothesis of correct specification is 0.0000 .
The third row of Table 1 includes the investment tax credit (but not depreciation allowances). Compared with the first row, the $\mathrm{J}$ statistic drops from 35.2-24.9. This suggests that including the investment tax credit substantially improves the specification. The results are similar when both the investment tax credit and depreciation allowances are included; the $\mathrm{J}$ statistic falls from 35.2-25.8 (As the second row of Table 1 suggests, the $\mathbf{J}$ statistic rises slightly when depreciation allowances are included; as later tables show, this result is quite general. It is possible that this is due to problems with the Salinger and Summers (1983) technique used to calculate $\mathrm{z}$. It is not clear how to test this conjecture without better quality data on the true depreciation allowances for tax purposes).

Taxes, risk and the effective interest rate: The timing of investment spending depends not only on the effective price of investment, but on the discount factor and expectations about the future. Tax policy can matter for two reasons. First, the trade-off between investing today and investing tomorrow depends on the corporate tax rate today and the expected corporate tax rate tomorrow. Second, the corporate tax rate may affect the interest rate which firms use in discounting the future.

Table 2 focuses on investment, taxes and the effective interest rate. In the first row, Eq. 14 is altered by removing the $\left(1-\tau_{t}\right)$ and $\left(1-\tau_{t+1}\right)$ terms everywhere. This removes all taxes from the Euler equation. In the second row, the corporate tax, investment tax credit and depreciation allowances are included. Adding these tax considerations improves the specification somewhat; the J statistic falls from 27.2-25.8. In the third row, the interest rate on T-bills is adjusted for taxes; in other words, $r_{t}$ is replaced with $r_{t} /\left(1-\tau_{t}\right)$. This results in a more substantial improvement in the specification. Compared with the second row, the J statistic drops from 25.8-19.3.

It has long been argued that weak evidence on the cost of capital may be due to problems in measuring the relevant interest rate. The traditional explanations involve problems such as correctly adjusting the interest rate for risk. To test this conjecture, Table 3 reports the same specifications as Table 2, except that the risk-free interest rate is replaced with a risk-adjusted rate (The results in Table 3 and 4) replace the interest rate on 30 day T-Bills with the interest rate on 30 day Banker's Acceptances. Over the sample period, the mean spread between these two interest rates is 104 basis points.). Unlike adjusting the interest rate for taxes, this change has little effect on the specification test. The $\mathbf{J}$ statistic in the first row of Table 3 is slightly higher than that in the first row of Table 2. 
Am. J. of Economics and Business Administration 2 (3): 210-220, 2010

Table 2: Investment, taxes and the effective interest rate (using a riskfree interest rate)

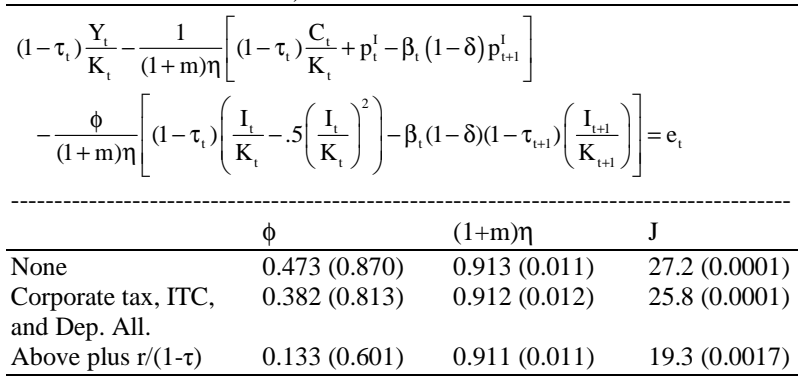

See the notes to Table 1 for the details of estimation. Robust standard errors are presented in parentheses below the parameter estimates. The number in parentheses below the $\mathrm{J}$ statistic is its marginal significance

Table 3: Investment, taxes and the effective interest rate (using a riskadjusted interest rate)

$$
\begin{aligned}
& \left(1-\tau_{\mathrm{t}}\right) \frac{\mathrm{Y}_{\mathrm{t}}}{\mathrm{K}_{\mathrm{t}}}-\frac{1}{(1+\mathrm{m}) \eta}\left[\left(1-\tau_{\mathrm{t}}\right) \frac{\mathrm{C}_{\mathrm{t}}}{\mathrm{K}_{\mathrm{t}}}+\mathrm{p}_{\mathrm{t}}^{\mathrm{I}}-\beta_{\mathrm{t}}(1-\delta) \mathrm{p}_{\mathrm{t}+1}^{\mathrm{I}}\right] \\
& -\frac{\phi}{(1+\mathrm{m}) \eta}\left[\left(1-\tau_{\mathrm{t}}\right)\left(\frac{\mathrm{I}_{\mathrm{t}}}{\mathrm{K}_{\mathrm{t}}}-.5\left(\frac{\mathrm{I}_{\mathrm{t}}}{\mathrm{K}_{\mathrm{t}}}\right)^{2}\right)-\beta_{\mathrm{t}}(1-\delta)\left(1-\tau_{\mathrm{t}+1}\right)\left(\frac{\mathrm{I}_{\mathrm{t}+1}}{\mathrm{~K}_{\mathrm{t}+1}}\right)\right]=\mathrm{e}_{\mathrm{t}}
\end{aligned}
$$

\begin{tabular}{|c|c|c|c|}
\hline & $\phi$ & $(1+m) \eta$ & $\mathrm{J}$ \\
\hline None & $0.654(0.583)$ & $0.913(0.011)$ & $27.7(0.0001)$ \\
\hline $\begin{array}{l}\text { Corporate tax, ITC, } \\
\text { and Dep. All. }\end{array}$ & $0.539(0.568)$ & $0.913(0.012)$ & $24.4(0.0005)$ \\
\hline Above plus $r /(1-\tau)$ & $0.361(0.497)$ & $0.912(0.011)$ & $19.2(0.0038)$ \\
\hline
\end{tabular}

See the notes to Table 1 for the details of estimation. Robust standard errors are presented in parentheses below the parameter estimates. The number in parentheses below the $\mathrm{J}$ statistic is its marginal significance

The implications for taxes remain the same. Including the corporate tax, the investment tax credit and depreciation allowances reduces the $\mathrm{J}$ statistic from 27.7-24.4; incorporating taxes in the discount factor yields a further reduction in the $\mathrm{J}$ statistic to 19.2.

Adjusting the market interest rate for risk has little effect on the tests on the effective price of investment. Comparing the first row of Table 1 with the first row of Table 4, the J statistic falls only slightly from 35.2-34.6. The main conclusions from Table 1 continue to hold: including the investment tax credit (or both the investment tax credit and depreciation allowances) substantially reduces the evidence of misspecification.

Summary: The results presented above provide evidence that taxes affect investment spending. Adjusting the effective price of investment for taxes (especially the investment tax credit) substantially reduces evidence of misspecification. Adjusting the interest rate for taxes yields a further substantial reduction in the evidence of misspecification. Unlike many previous studies in which tax effects had to be inferred from tax terms which entered in
Table 4: Investment, taxes and the effective price of investment (using a risk-adjusted interest rate)

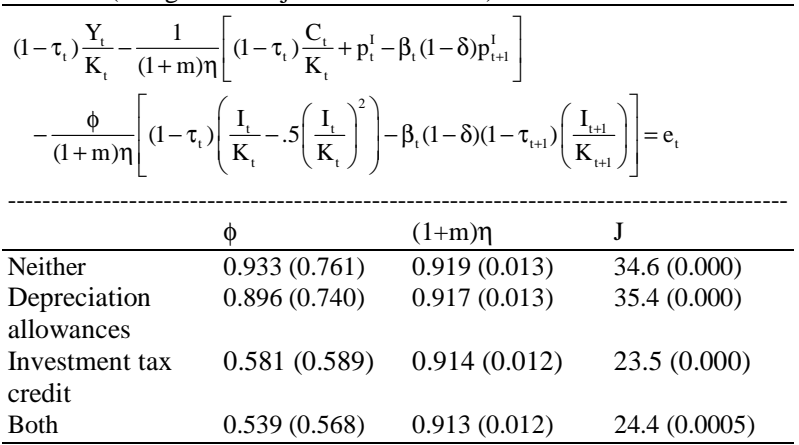

See the notes to Table 1 for the details of estimation. Robust standard errors are presented in parentheses below the parameter estimates. The number in parentheses below the $\mathbf{J}$ statistic is its marginal significance

combination with other variables (such as output or stock prices), the evidence presented here is direct. It comes from comparing specifications in which the only change is omitting or including tax variables.

Finance constraints and the Euler equation: One traditional explanation for the weak influence of the cost of capital on investment is measurement error in the market interest rate. This can be distinguished from a more subtle problem; when firms face binding finance constraints, the shadow interest rate may diverge from the market interest rate. Below, this is illustrated using the first-order conditions from the firm's optimization problem. This section also illustrates how finance constraints might lead the investment Euler equation to fail and how we can construct two types of tests for this possibility.

To capture the idea that, under asymmetric information, firms may face finance constraints, we consider the case where firms face a debt capacity constraint. The first order condition for debt in this case is:

$$
\begin{gathered}
1-\beta_{t}\left[\left(1-\tau_{t+1}\right) r_{t}+1\right]-\omega_{t}=0 \\
\omega_{t}\left(B_{t}-B^{*}\right)=0, \omega_{t} \geq 0
\end{gathered}
$$

Where:

$\omega=$ The Lagrange multiplier on the debt constraint $\mathrm{B}^{*}=$ The debt limit of the firm

To see the intuition for this result, note that when the constraint is not binding, $\omega=0$. If the constraint does not bind, the discount rate is:

$$
\beta=\frac{1}{1+\left(1-\tau_{t+1}\right) r_{t}}
$$


When the constraint binds, the firm faces the lower discount factor:

$$
\beta_{t}=\frac{1-\omega_{t}}{1+\left(1-\tau_{t+1}\right) r_{t}}
$$

Another way to think of this is that when a firm finds it difficult to obtain external financing, the market interest rate is a poor proxy for the shadow cost of external financing. The relevant discount rate for the firm may be much higher than the market interest rate. Of course, under symmetric information, prices would adjust to clear the market. But, as Stiglitz and Weiss (1981) have shown, under asymmetric information price adjustments may not be sufficient to clear the market.

This specification leads to a nice test for the existence of finance constraints. If the firm faces a binding constraint on its external financing, Eq. 12 will be misspecified; more precisely, the error will no longer arise exclusively from the difference between actual and expected values. There will be an additional term which arises from the non-zero Lagrange multiplier on the debt constraint:

$$
\begin{aligned}
& \left(1-\tau_{t}\right) \frac{p_{t} Y_{t}}{K_{t}}-\frac{1}{(1-\psi) \eta}\left[\begin{array}{l}
\left(1-\tau_{t}\right) \frac{C_{t}}{K_{t}}+\left(1-k_{t}-\tau_{t} z_{t}\right) p_{t}^{1} \\
-\left(\frac{1}{1+\left(1-\tau_{t+1}\right) r_{t}}\right)(1-\delta)\left(1-k_{t+1}-\tau_{t+1} z_{t+1}\right) p_{t+1}^{I}
\end{array}\right] \\
& -\frac{\phi}{(1-\psi) \eta}\left[\begin{array}{l}
\left.\left(1-\tau_{t}\right)\left(\frac{I_{t}}{K_{t}}-.5\left(\frac{I_{t}}{K_{t}}\right){ }^{2}\right)-\left(\frac{1}{1+\left(1-\tau_{t+1}\right) r_{t}}\right)\right]=e_{t} \\
(1-\delta)\left(1-\tau_{t+1}\right)\left(\frac{I_{t+1}}{K_{t+1}}\right)
\end{array}\right] \\
& +\omega_{t}\left(\frac{1}{1+\left(1-\tau_{t+1}\right) r_{t}}\right)\left[\begin{array}{l}
\frac{1}{(1-\psi) \eta}(1-\delta)\left(1-\mathrm{k}_{t+1}-\tau_{t+1} z_{t+1}\right) p_{t+1}^{1}+ \\
\frac{\phi}{(1-\psi) \eta}(1-\delta)\left(1-\tau_{t+1}\right)\left(\frac{I_{t+1}}{K_{t+1}}\right)
\end{array}\right]
\end{aligned}
$$

Variables in the information set at time t- 1 may be correlated with this component of the error. Under the null hypothesis of symmetric information (so firms do not face finance constraints), this specification is correct; if firms are constrained, the specification is incorrect and may be rejected by a test of the over identifying restrictions (In US aggregate data, Gertler et al. (1991) reject the null hypothesis of symmetric information).

Although the specification test described in the previous paragraph is elegant, it has two important limitations. First, rejection of the over identifying restrictions might be a result of other forms of misspecification. Second, rejection of the null hypothesis is a statistical result; it gives us little sense of the quantitative importance of finance constraints. We can obtain a more informative test by parameterizing the Lagrange multiplier on the external finance constraint. Finance constraints arise when the internal net worth of the firm is insufficient to cover its desired investment spending. As the agency cost model of Gertler et al. (1991) illustrates, shocks to net worth should be reflected in the risky spread (the risky spread is defined as the difference between the interest rates on two securities of equal maturity, one of which involves a greater degree of risk. In the empirical work, the risky spread is the difference between the interest rates on 30 day T-Bills and 30 day Bankers' Acceptances). Thus the shadow cost of external financing should be related to the risky spread. To capture this, we assume a simple linear relationship:

$\omega_{t}=\gamma_{0}+\gamma_{1} S_{t-1}$

where, $\mathrm{S}_{\mathrm{t}-1}$ is the risky spread. By substituting this functional form for $\omega$, we can rewrite the Euler equation for the constrained case with the terms involving $\omega$ on the left-hand side:

$$
\begin{aligned}
& \left(1-\tau_{t}\right) \frac{p_{1} Y_{t}}{K_{t}}-\frac{1}{(1-\psi) \eta}\left[\begin{array}{l}
\left(1-\tau_{t}\right) \frac{C_{t}}{K_{t}}+\left(1-k_{t}-\tau_{t} z_{t}\right) p_{t}^{t} \\
-\left(\frac{1}{1+\left(1-\tau_{t+1}\right) r_{t}}\right)\left(1-\left(\gamma_{0}+\gamma_{1} S_{t-1}\right)\right)(1-\delta)\left(1-k_{t+1}-\tau_{t+1} z_{t+1}\right) p_{t+1}^{t}
\end{array}\right] \\
& -\frac{\phi}{(1-\psi) \eta}\left[\begin{array}{l}
\left(1-\tau_{t}\right)\left(\frac{I_{t}}{K_{t}}-.5\left(\frac{I_{t}}{K_{t}}\right)^{2}\right) \\
-\left(\frac{1}{1+\left(1-\tau_{t+1}\right) r_{t}}\right)\left(1-\left(\gamma_{0}+\gamma_{1} S_{t-1}\right)\right)(1-\delta)\left(1-\tau_{t+1}\right)\left(\frac{I_{t+1}}{K_{t+1}}\right)
\end{array}\right]=\mathrm{e}_{t}
\end{aligned}
$$

We are left with an expectational error on the righthand side which should be orthogonal to time t-1 variables and should therefore pass a specification test. Moreover, the estimates of $\gamma_{1}$ tell us how large an effect finance constraints have on the shadow cost of external financing (using this parametric version of the agency cost model in US aggregate data, Gertler et al. (1991) find that a 50 basis point increase in the risky spread roughly doubles the effective discount rate).

Empirical estimates of the Euler equation allowing for finance constraints: Below we have two main objectives. First, it tests whether allowing for finance constraints improves the specification of the investment Euler equation. Second, it examines whether including tax terms further improves the specification, even after allowing for finance constraints.

Finance constraints and the cost of capital: Under finance constraints, the shadow interest rate can diverge from the market interest rate. To derive (20), the 
Lagrange multiplier on the firm's borrowing constraint was parameterized using the insight that shocks to net worth should be reflected in the risky spread. The coefficient which captures this effect is $\gamma_{1}$. If $\gamma_{1}$ is positive, this suggests that the shadow discount factor diverges from the market interest rate, since (ignoring taxes for the moment):

$\beta_{t}=\frac{1-\omega_{t}}{1+r_{t}}=\frac{1-\left(\gamma_{0}+\gamma_{1} S_{t-1}\right)}{1+r_{t}}$

The first equality comes from Eq. 17 and the second from Eq. 19.

Table 5 presents estimates of the Euler Eq. 20, derived above, which allows for finance constraints. The estimates of $1 \mathrm{~g}$ are positive and highly statistically significant, suggesting that finance constraints bind, at least for some of the firms in the sample $(\mathrm{Ng}$ and Schaller (1996) find that finance constraints tend to bind more for firms which find it difficult to credibly communicate private information. This is consistent with theoretical models which suggest that asymmetric information can lead to finance constraints. For further discussion and references, the survey by Gertler (1988)). The sign, magnitude and statistical significance of $\gamma_{1}$ are robust to the inclusion or omission of tax parameters.

The estimated coefficient on the spread is 11.9 (with a standard error of 3.5). To give a sense of how large the effect is, consider a one standard deviation increase in $\mathrm{S}_{\mathrm{t}-1}$; over the 1973-86 period, this is equal to an increase of 65 basis points. Such an increase in the risky spread has the same effect on the shadow cost of finance as a 770 basis point increase in real interest rates. This increase in shadow cost is almost twice the mean real interest rate of $4 \%$.
The estimates of $\gamma_{1}$ imply that the shadow discount rate diverges dramatically from the market interest rate. This suggests that the market interest rate may serve as a poor proxy for the discount rate which firms use in assessing tradeoffs between one period and the next. In other words, there is an important errors-in-variables problem with conventional measures of the cost of capital. It is well known that, in a linear regression, measurement error tends to bias the coefficient on the error-ridden variable towards zero. To the extent that previous research on the cost of capital has used the market interest rate, the results in Table 5 suggest that the failure to find strong evidence on the cost of capital may be attributable to finance constraints.

A formal test which compares the over identifying restrictions between two models which involve a different number of parameters is described by Newey and West (1987). (For an example of an empirical application, see Cochrane (1996)). The intuition for the test is straightforward. If a model is incorrectly specified, the $\mathrm{J}$ statistic will tend to be large; the difference in $\mathrm{J}$ statistics between two models provides a test of whether the improvement in specification is statistically significant (the test requires the same weighting matrix to be used in estimating both models; we use the weighting matrix for the unrestricted model). The difference in $\mathrm{J}$ statistics is distributed $\mathrm{x}^{2}$, with degrees of freedom equal to the number of omitted parameters. The model with no finance constraints involves two fewer parameters, so the test statistic has two degrees of freedom. The test statistic is 16.9, which implies a marginal significance level of 0.0002 (this value of the test statistic corresponds to the inclusion of the tax parameters reported in the final row of Table 5).

Table 5: Finance constraints, taxes and the effective price of investment

$$
\begin{gathered}
\left(1-\tau_{\mathrm{t}}\right) \frac{\mathrm{Y}_{\mathrm{t}}}{\mathrm{K}_{\mathrm{t}}}-\frac{1}{(1+\mathrm{m}) \eta}\left[\left(1-\tau_{\mathrm{t}}\right) \frac{\mathrm{C}_{\mathrm{t}}}{\mathrm{K}_{\mathrm{t}}}+\mathrm{p}_{\mathrm{t}}^{\mathrm{I}}-\left(\frac{1}{1+\mathrm{r}_{\mathrm{t}}}\right)\left(1-\left(\gamma_{0}+\gamma_{\mathrm{t}} \mathrm{S}_{\mathrm{t}-1}\right)\right)(1-\delta) \mathrm{p}_{\mathrm{t}+1}^{\mathrm{I}}\right] \\
-\frac{\phi}{(1+\mathrm{m}) \eta}\left[\begin{array}{l}
\left(1-\tau_{\mathrm{t}}\right)\left(\frac{\mathrm{I}_{\mathrm{t}}}{\mathrm{K}_{\mathrm{t}}}-.5\left(\frac{\mathrm{I}_{\mathrm{t}}}{\mathrm{K}_{\mathrm{t}}}\right)^{2}\right)-\left(\frac{1}{1+\mathrm{r}_{\mathrm{t}}}\right) \\
\left(1-\left(\gamma_{0}+\gamma_{1} \mathrm{~S}_{\mathrm{t}-1}\right)\right)(1-\delta)\left(1-\tau_{\mathrm{t}+1}\right)\left(\frac{\mathrm{I}_{\mathrm{t}+1}}{\mathrm{~K}_{\mathrm{t}+1}}\right)
\end{array}\right]=\mathrm{e}_{\mathrm{t}}
\end{gathered}
$$

\begin{tabular}{llllll}
\hline Specification & $\varphi$ & $(1+\mathrm{m}) \eta$ & $\gamma_{0}$ & $\gamma_{1}$ & $\mathrm{~J}$ \\
\hline Neither & $-0.783(0.414)$ & $0.918(0.010)$ & $0.080(0.093)$ & $10.32(2.090)$ & $13.5(0.0092)$ \\
Depreciation allowances & $-0.847(0.433)$ & $0.916(0.011)$ & $0.079(0.104)$ & $10.856(2.349)$ & $13.8(0.0081)$ \\
Investment tax credit & $-1.096(0.534)$ & $0.917(0.012)$ & $0.060(0.129)$ & $10.845(2.997)$ & $10.8(0.0286)$ \\
Both & $-1.170(0.575)$ & $0.915(0.012)$ & $-0.072(0.150)$ & $11.872(3.513)$ & $11.1(0.0257)$ \\
\hline
\end{tabular}

See the notes to Table 1 for the details of estimation. Robust standard errors are presented in parentheses below the parameter estimates. The number in parentheses below the $\mathbf{J}$ statistic is its marginal significance 
Table 6: Finance constraints, taxes and the effective interest rate

$$
\begin{gathered}
\left(1-\tau_{\mathrm{t}}\right) \frac{\mathrm{Y}_{\mathrm{t}}}{\mathrm{K}_{\mathrm{t}}}-\frac{1}{(1+\mathrm{m}) \eta}\left[\left(1-\tau_{\mathrm{t}}\right) \frac{\mathrm{C}_{\mathrm{t}}}{\mathrm{K}_{\mathrm{t}}}+\mathrm{p}_{\mathrm{t}}^{\mathrm{I}}-\left(\frac{1}{1+\mathrm{r}_{\mathrm{t}}}\right)\left(1-\left(\gamma_{0}+\gamma_{1} \mathrm{~S}_{\mathrm{t}-1}\right)\right)(1-\delta) \mathrm{p}_{\mathrm{t}+1}^{\mathrm{I}}\right] \\
-\frac{\phi}{(1+\mathrm{m}) \eta}\left[\begin{array}{l}
\left(1-\tau_{\mathrm{t}}\right)\left(\frac{\mathrm{I}_{\mathrm{t}}}{\mathrm{K}_{\mathrm{t}}}-.5\left(\frac{\mathrm{I}_{\mathrm{t}}}{\mathrm{K}_{\mathrm{t}}}\right)^{2}\right)-\left(\frac{1}{1+\mathrm{r}_{\mathrm{t}}}\right) \\
\left(1-\left(\gamma_{0}+\gamma_{\mathrm{t}} \mathrm{S}_{\mathrm{t}-1}\right)\right)(1-\delta)\left(1-\tau_{\mathrm{t}+1}\right)\left(\frac{\mathrm{I}_{\mathrm{t}+1}}{\mathrm{~K}_{\mathrm{t}+1}}\right)
\end{array}\right]=\mathrm{e}_{\mathrm{t}}
\end{gathered}
$$

\begin{tabular}{|c|c|c|c|c|c|}
\hline Specification & $\varphi$ & $(1+m) \eta$ & $\gamma_{0}$ & $\gamma_{1}$ & $\mathrm{~J}$ \\
\hline None & $-1.026(0.500)$ & $0.916(0.010)$ & $-0.079(0.218)$ & $19.886(6.041)$ & $13.6(0.0088)$ \\
\hline Corporate tax, ITS and Dep. All. & $-1.170(0.575)$ & $0.915(0.012)$ & $-0.072(0.150)$ & $11.872(3.513)$ & $11.1(0.0257)$ \\
\hline Above plus $r /(1-\tau)$ & $-1.236(0.612)$ & $0.914(0.013)$ & $-0.096(0.163)$ & $9.841(3.663)$ & $10.0(0.0403)$ \\
\hline
\end{tabular}

See the notes to Table 1 for the details of estimation. Robust standard errors are presented in parentheses below the parameter estimates. The number in parentheses below the $\mathrm{J}$ statistic is its marginal significance

Tax effects under finance constraints: Table 5 presents GMM estimates of the Euler equation allowing for finance constraints. The first row is estimated with neither the investment tax credit nor depreciation allowances included in the effective price of investment. The J statistic is 13.5, which implies rejection of the null hypothesis of correct specification at the 0.0092 level.

The third row of Table 5 includes the investment tax credit (but not depreciation allowances). Compared with the first row, the $\mathrm{J}$ statistic drops from 13.5-10.8. This suggests that including the investment tax credit substantially improves the specification. The results are similar when both the investment tax credit and depreciation allowances are included; the $\mathrm{J}$ statistic falls from 13.5-11.1.

Table 6 focuses on investment, taxes and the effective interest rate. In the first row, Eq. 20 is altered by removing all the tax terms. In the second row, the corporate tax, investment tax credit and depreciation allowances are included. Adding these tax considerations improves the specification; the $\mathrm{J}$ statistic falls from 13.6-11.1. In the third row, the interest rate is adjusted for taxes; this results in a further improvement in the specification. Compared with the second row, the J statistic drops from 11.1-10.0.

\section{CONCLUSION}

The objective of this study is to determine whether the cost of capital affects investment. The evidence presented in the section entitled "Results" shows that including taxes in the investment Euler equation reduces evidence of misspecification. In particular, including the investment tax credit, the corporate tax rate and interest deductibility, respectively, all lead to less evidence of misspecification than omitting these tax considerations. These results suggest that the cost of capital (specifically, the tax system) influences investment.
It has been suggested that one reason why previous research has failed to find strong evidence for the cost of capital is the difficulty of correctly measuring the relevant interest rate. In this study, two types of problems in measuring the relevant interest rate are distinguished. First, it may be difficult to measure the market interest rate, perhaps because the researcher is not sure of the appropriate risk adjustment or because of the difficulty in translating observable nominal interest rates into unobservable real interest rates. The results suggest that problems with measuring the market interest rate may not be very important; for example, adjusting for risk has virtually no effect on the evidence of misspecification. Second, the shadow interest rate may diverge from the market interest rate if firms face finance constraints. There is strong evidence that this measurement problem is both economically and statistically important. A Newey and West (1987) test between the specification which allows for finance constraints and the specification without finance constraints rejects the latter at the 0.0002 level. The variation in the shadow interest rate estimated from the model is very large compared to the variations in the market interest rate.

After allowing for finance constraints, there is further evidence that taxes affect investment. In specifications which incorporate finance constraints, omitting the investment tax credit, the corporate tax rate, or interest deductibility leads to larger $\mathrm{J}$ statistics (i.e., more evidence of misspecification) than specifications which include these tax considerations.

\section{REFERENCES}

Abel, A.B. and O.J. Blanchard, 1986. The present value of profits and cyclical movements in investment. Econometrica, 54: 249-273. DOI: $10.2307 / 1913150$ 
Bertola, G. and R.J. Caballero, 1994. Irreversibility and aggregate investment. Rev. Econ. Stud., 61: 223-246. DOI: $10.2307 / 2297979$

Chirinko, R.S., 1993. Business fixed investment spending: A critical survey of modeling strategies, empirical results and policy implications. J. Econ. Literature, 31: 1875-1911. DOI: 10.2307/4786849

Cochrane, J., 1996. A cross-sectional test of an investment-based asset pricing model. J. Political Econ., 104: 572-621. DOI: 10.1086/262034

Devereux, M., M. Keen and F. Schiantarelli, 1994. Corporation tax asymmetries and investment : Evidence from U.K. panel data. J. Public Econ., 53: 395-418. DOI: $10.2307 / 7829438$

Fazzari, S.M., R.G. Hubbard and B.C. Petersen, 1988. Financing constraints and corporate investment. Brook. Papers Econ. Activity, 1988: 141-206. DOI: 10.2307/2534426

Gertler, M., 1988. Financial structure and aggregate economic activity: An overview. J. Money, Credit Bank., 20: 559-588. DOI: 10.2307/1992535

Gertler, M., R.G. Hubbard and A. Kashyap, 1991. Interest rate Spreads, Credit Constraints and Investment Fluctuations: An Empirical Investigation. In: Financial Markets and Financial Crises, Hubbard, R.G. (Ed.). University of Chicago Press for NBER, Chicago.

Hansen, L.P., 1982. Large sample properties of generalized method of moment estimators. Econometrica, 50: 1029-1054. DOI: $10.2307 / 1912775$

Hubbard, R.G. and A.K. Kashyap, 1992. Internal net worth and the investment process: An application to U.S. agriculture. J. Political Econ., 100: 506534. DOI: $10.1086 / 261827$
Kashyap, A.K, O.A. Lamontand and J.C. Stein, 1994. Credit conditions and the cyclical behavior of inventories. Q. J. Econ., 109: 565-592. DOI: $10.2307 / 2118414$

Newey, W.K. and K.D. West, 1987. Hypothesis testing with efficient method of moments estimation. Int. Econ. Rev., 28: 777-787. DOI: 10.2307/2526578

$\mathrm{Ng}, \mathrm{S}$. and H. Schaller, 1996. The risky spread investment and monetary policy transmission: Evidence on the role of asymmetric information. Rev. Econ. Stat., 78: 375-383. DOI: $10.2307 / 2109784$

Pindyck, R., 1991. Explaining and Forecasting Aggregate Investment Expenditures: Distributed Lags and Autocorrelation. In: The Practice of Econometrics: Classic and Contemporary, Berndt, E.R. (Ed.). Addison-Wesley Publishing Company, Reading, Massachusetts, pp: 224-305.

Salinger, M.A. and L. Summers, 1983. Tax Reform and Corporate Investment: A Microeconomic Simulation Study. In: Behavioral Simulation Methods in Tax Policy Analysis, Martin F. (Ed.). University of Chicago Press, Chicago, pp: 369-462.

Schaller, H., 1990. A Re-examination of the Q theory of investment using US firm data. J. Applied Econ., 5: 309-325. DOI: 10.1002/jae.3950050402

Stiglitz, J.E. and A. Weiss, 1981. Credit rationing in markets with imperfect information. Am. Econ. Rev., 71: 393-410. DOI: 10.2307/3758939

Summers, L.H., 1981. Taxation and corporate investment: A Q-theory approach. Brook. Econ. Activity, 1981: 67-127. DOI: 10.2307/2534397

Whited, T.M., 1992. Debt, liquidity constraints and corporate investment: Evidence from panel data. J. Finance, 25: 1425-1460. DOI: $10.2307 / 2328946$ 